\title{
XIX. Essays on chemical philosophy
}

\section{Mr. M. Allen}

To cite this article: Mr. M. Allen (1817) XIX. Essays on chemical philosophy , Philosophical Magazine Series 1, 49:226, 81-85, DOI: $10.1080 / 14786441708637846$

To link to this article: http://dx.doi.org/10.1080/14786441708637846

$$
\text { 曲 Published online: } 27 \text { Jul } 2009 .
$$

Submit your article to this journal

LII Article views: 2

Q View related articles $\asymp$ 
XIX. Essays on Chemical Philosophy. By Mr. M. Allen, Lecturer.

Essay I.

$I_{T}$ is intended in these Essays to offer a brief outline of the laws and principles of natural science; and as some of the ideas proposed to be offered, may be found to differ from the principles and reasoning which have becn advanced by others, the reader is requested not to be hasty in either receiving or rejecting what may be advanced, but to suspend his decision till the way has been cleared for their statement, and their application to chemical affinity, electricity, caloric, light, astronomy, and the immense detail of facts in Nature and in chemical or artificial operations, has been exbibited.

The bare mention of the subject precludes the necessity of argument to show its importance.-It is the desideratum of science. It is true that the operations and effects of the power of Nature, called attraction, have been submitted to rigid and mathematical calcuiation : but it is equally true, that only by a misnomer have these been denominated the lau's of its action; for they merely point out the uniformity of those effects which the laws and principles of its action produce. The same misapplication of the words "laws and principles" is committed in applying them to those circumstances by which the operation of these laws and principles is facilitated, opposed or modified, such as pulverization, solution, gravity, \&c. The subject therefore requires, as has been said, no argument to establish its importance, however desirable it might be that more adequate powers than the writer can boast had undertaken the present task. He feels however no apprehensions for the fate of his attempt, for truth is the object he aims at ; and so far as he may succeed in making this manifest, he knows that, in this philnsophical age, he has nothing to fear from the hostility of prejudice. All opposition, however, is not prejudice. Opposition often exerts itself beneficially in defence of truth; but prejudice resists and presumes to answer before it has examined and understood the things it hal prefletermined to oppose.

Without firther preface, I will at once proceed to the classification or division of scjence, intended to be pursued, and to state the reasons for adoptiug the names and arrangements employed in such classification or division;-and, as the primary head, what relates to attraction - at tractive agencies-and passive substances.

Vol.49. No.226. Fel. 1817. F I. At- 


\section{Attraction.}

Attraction, in common langrage, is applied both to the cause, and to the effect which that cause produces; and though philosophers now use it in a more abstract and arbitrary manner, yet they appear to have chosen it in the first instance, rather as descriptive of effects, than as expressive of any abstract idea they could form or convey of its essence. In this sense Newton considererl the word; and though he adopted and applied it, from the want of a more suitable word, in the most enlarged manner, he complained of those who mistook his reasons for this, and evidently considered attraction as only the effect of anothes power *. The term attraction, as well as the term repulsion, can express only the mere property of a power, and is therefore an improper name for the power itself; and philosophers would render an important service to science, were they unanimously to consent to introduce for the latter some other word more defined and correct in its application, as the vis natura, or cause producing attraction and repulsion, or attractive and repulsive or other effects. The reasons for this will appear to more advantage by and by. Let it suffice at present, to state, to define and restrict the term, that the reader may understand the sense invariably meant to attach to it in the remarks which may be laid before him in these Essays. The vis natura is employed as a term to express the sole grand power or principle of Nature; and, agreeably to this view, is defined to be that "cause which produces all the motion and union of matter."

This general definition is offered, from a conviction that this power is alone sufficient to explain all the phænomena of Nature and of Art. Let it not be imagined, that it is intended to express or to determine the nature or essence, or even all the properties, of such a power; or, that this power consists of one element alone; for it is much more probable that its constituents way form the basis of all matter: it is not however intended that its compound nature shall be contended for or maintained. Facts alone are the only sure foundation on which the philosopher should attempt to establish his theory. Let the phrnomena of facts be stated correctly, and their number. Can it be doubted, that with due attention they will be found to arrange themselves under one general principle, regulated by the same laws, modified by eircumstances? $\rightarrow$ Such a generalization of nature can alone, in my opinion, furnish a true theory. An artist copies the forms, colours, and diversified appearances of nature-

* See Attrartion, Johnson's large Dictionary, and last page of Pembercon' View of Sir Isaac Newton's Philosophy. 
the true philosopher, the servant of nature, traces the operation and endeavours to ascertain the laws of that power by which all these are produced.

In this sense then I contend, that the power which in chemistry binds and unites matter together, is the same power that carries matter from one point to another; and 1 therefore define it to be "that power which produces all the motion and union of matter." According to this view of its operations, it is not necessary to call to the aid of science a repulsive or projectile power, in order to explain either the minute or extended movements and changes, or "motion and union," of matter, which are for ever going on in every part of the creation.Niture is but another word for this power. The operations are the objects of all natural science; and circumstances alone constitute the difference of each of our artificial divisions of human knowledge. It has been said " that electricity, caloric and light are powers by which repulsion is produced; and the proofs alduced in support of this opinion are, that, by the application of these in an increased degree, "repulsion is established between the particles of matter, and the force of attraction is overcome:" and hence, it is said, "solids become fluids, and fluids gases." But these effects, as well as every other attributed to a repulsive power, may, it is believed, be better explained without the introduction of more than one universal power of Nature.

Repulsion is a term which can never be used with propriety as expressive of a distinct cause of effects, contrary and in opposition to those of attraction, if by that word we mean the power of Nature. It may indeed be used as a descriptive terin, and to this it ought to be restricted. We may speak of certain powers having a repalsive effect on matter, but never. (uith propriety) of repulsion itself as the power or primary cause of any effect whalever.

It is said, "the magnetic and electric attractions so far agree with the attraction of gravity as to operate at sensible distances, and even, as has been attempted to be proved, according to the same law;" and yet these powers with caloric and light are classed together in the same system of chemistry*, "as the powers by which repulsion is produced." In fact, this definition of repulsion is not the definition of it as a cause, but of certain effects of other powers, to which the name "repulsion" is atplied as descriptive of their kind or mode of operation. And in this sense alone its application is proper. The definition says in direct words, " Electricity, caloric, and light, are (themselves) the pou'ers by which repulsion (itself) is produced;" and yet to

* Dr, Murray's System, 1st, 2d, 3rd and 4th editions. 
the consideration of this word, not as a descriptive term of effects, but as a name for a distinet power of causation, five pages are devoted for one that is given to attraction, as the grand and universal power of Nature, of whose effects Newton traced with an unerring hand the grand and extensive outlines.

The same cause will always produce the same effects, the circumstances being the same. Now these powers, electricity, caloric, and light, are invariabiy treated as powers principally concerned in the attractions which take place anong the particles of matter, or chemical attraction. How then are they said to produce effects the very reverse of attraction? In fact, this confusion has originated in the arbitrary and undefined application of the term altraction: it is one cause which produces different effects, either (as will hereafter be proved in detail) from difference of circumstances, or in the degree of the same powerfrom these causes arises its two-fold action, of carrying bodies and the particles of bodies in one direction, and drawing them in another.

Attraction binds matter together, and the same power (I contend) carries it from one point to another. The latter is the repulsion of chemists, but the repulsive effects of Nature; and these varied modifications of the same power serve but to exhibit so many instances of the superior and all-pervading omnipotent influence of that power. Artificial and arbitrary distinctions have made Science and Nature two very different things. Chemistry has been defined as "the science which treats of the insensible motions of matter," or say " of the minute and intricate changes of Nature." Now, if the minute and intricate changes of Nature are connected with her sublime and extended movements, -if minute atoms and celestial masses are moved by the same power, regulated by the same laws, and merely modified by circumstances, - then this definition is defective, and it only applies partially. If then it be allowed that the object of chemistry is to examine the one, and that not only the most difficult, but which must contain the first principles of the other, that other and subsequent part of natural science is a continuation of the first, and they ought to be considered as parts of one whole: Chemical philosophy* 1 would therefore define to be that science which investigates the movements and changes of Nature, and endeavours to ascertain the laws and principles by which these effects are produced. This is its proper olject-it is the golden key by which we unlock the secrets of Nature, and are enabled to discover the laws of that power' by which Nature produces all her operations.

* Definitions of its application to practical chemistry and astronomy witl be given hereafter.

Distinctions 
Distinctions are made between it and other branches of seience, making it a separate and insulated portion of human knowkedge. Whereas every student must have observed that, in every advance he makes in chemistry, his views of Nature are enlarged, and he is ehabled more correctly to ascertain the laws and principles of the operation of the grand power, the cause of all the motion and union of matter. The further therefore we advance, the more these artificial divisions of science will be confounded, and the more certainly will be preindicated a time when they will te lost in the magnitude and splendow of truth.

Notwithstanding these partial definitions and arbitrary distinctions, every description we have of the powers, the objects, and the application of this science does more justice to its importance, and develops, not an insulated portion of linowledge, but, in fact, all that we include by the phrase Natural Philosophy, and, more than this, the word Chemistry implied and included. I am firmly persuaded that inproved chemistry, or, which is the same thing, correct views on the laws which attraction or the power of Nature observes, will simplify science, and render its acquirement easy, delighttul, and rapid. It will not appear strange that I should hold chemistry destined to this hollour, after what has already been said; nor do I argie so much from the wonders it has already accomplished, as from the nature of the science. Its professed object is to remove the veil from the face of Nature, - to discover the wonderful properties of matter,- -and to become acquainted with the mysterious power by which they are made to produce the various movements and changes in the order of things, as well those of Nature, as those of art in civilized society. Does it not comprehend the elements of every science? is it not the centre and circumference of a great circle, in which they all have their origin and termination? Can it be otherwise, when its sole consideration is the primum molile of matter?

[To be continued.]

XX. On Barometric Pressure; Whether affected by being posited beneath a Balloon in the Act of ascending or descending? By A Correspondent.

\section{To Mr. Tilloch.}

Sir, $-A$ conversation among some friends a few evenings since occurred, respecting barometrical pressure; and whilst endeavouring to account for some of the phænomena presented by 